U.S. DEPARTMENT OF INTERIOR GEOLOGICAL SURVEY

\title{
A COMPARISON OF STATIONARY AND CONTINUOUS GAMMA-RAY SPECTRAL DATA WITH CORES IN GRANITES
}

By

Ulrich Schimschal, Denver Colorado

Open-File Report 91-101

1991

This report is preliminary and has not been reviewed for conformity with U.S. Geological Survey editorial standards and nomenclature. 


\title{
A COMPARISON OF STATIONARY AND CONTINUOUS \\ GAMMA-RAY SPECTRAL DATA WITH CORES IN GRANITES
}

\author{
By Ulrich Schimschal \\ U.S. Geological Survey \\ Denver, Colorado
}

\begin{abstract}
This report describes a study undertaken to compare quantitative gamma-
\end{abstract} ray spectral analyses of naturally occurring radioisotopes from borehole logs and from cores in the laboratory. Continuous logging was accomplished by centering selected energy windows on the 1.46 megaelectronvolts peak for potassium-40, 1.76-megaelectronvolt peak for uranium-238, and the 2.62 megaelectronvolt peak for thorium-232. In addition, a number of stationary spectra were obtained at depths corresponding to preselected core locations. The drill hole used for the study was the Granite Mountain No. 2 test borehole near Jeffrey City, Wyoming. The borehole, entirely in granitic rocks, was logged to a depth of 463 meters using a sodium-iodide crystal, with a diameter of 32 milli-meters and a length of 100 millimeters. The crystal was calibrated with point sources. The results indicate the advantages of running a continuous log in conjunction with stationary spectra or cores in order to determine boundaries of the anomalies. Quantitative results for cores and inhole stationary spectra are in reasonable agreement for both potassium and thorium. The scatter obtained for uranium may be indicative of nonhomogeneous distribution in the rock matrix or possibly chemical redistribution with time. 


\section{INTRODUCTION}

Several authors (Conaway et al., 1980 and Lovborg et al., 1980) have published papers concerning the quantitative interpretation of gamma-ray spectral logging data. In this paper, the interpretation is based on the calculated effect of a single given horizontal layer containing homogeneously distributed radioisotopes on a cylindrical probe centered in a drill hole. The purpose of this paper is to compare borehole radiolsotope concentrations derived by this method to those determined in the laboratory from cores. Continuous logs were run in addition to the stationary logs to help define layer thicknesses.

This paper also fllustrates that reasonable accuracy may be achieved by simple calibration procedures in combination with theoretically derived environmental corrections.

Field conditions, equipment, and procedures

Granite Mountain No. 2 test borehole (fig. 1) was drilled to a depth of $463 \mathrm{~m}$ (meters) with a diameter of $7.62 \mathrm{~cm}$ (centimeters). The borehole probe used to $\log$ the test hole was $48 \mathrm{~mm}$ (millimeters) in diameter, housing a $32 \times 100-m m$ sodium-iodide crystal. To aid in energy calibration, a barium-133 test source was placed below the crystal. Field data were acquired with a 1,024 channel pulse-height spectral analyser and recorded on 7-tract digital magnetic tape. The probe was centered in the borehole. Stationary spectra were obtained for 500 seconds.

For the continuous $\log$, probe speed was set at 3 meters per minute. Due to the equipment used, three separate logging runs had to be made, each with a different window. The windows were centered on the $1.46-\mathrm{MeV}$ (megaelectronvolt) peak for potassium-40, the $1.76-\mathrm{MeV}$ peak for uranium-238, 


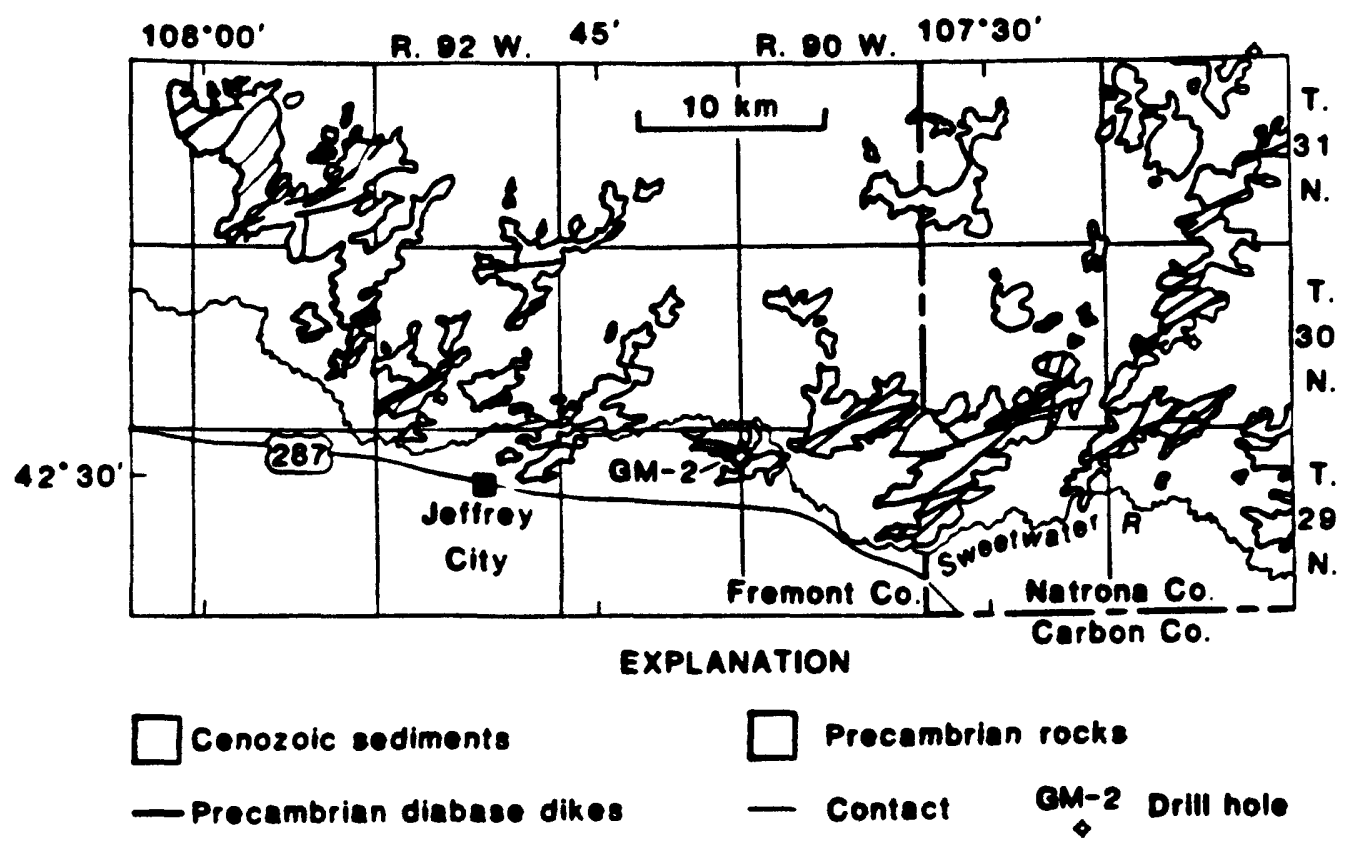

Figure 1.--Location of Granite Mountain test drill hole (modified from Stuckless et al., 1977). 
bismuth-214 daughter, and the 2.62-MeV peak for thorium-232, thallium-208 daughter. The probe was stopped periodically in the hole, and the equipment was manually recalibrated for drift, using the barium-133 peak obtained from the enclosed calibration source.

\section{Calibration procedures}

Calibration of the probe was accomplished by matching experimental data obtained from a point source placed at various distances from the probe to a theoretical curve calculated for geometric effects (Schimschal, 1980a). In this calibration procedure, the point source is positioned at various distances from the crystal axis, and a number of measurements are made. Theoretical values are then calculated for this experimental configuration. The theoretical curve is multiplied by an instrument coefficient to obtain a best fit between the experimental and theoretical curves. This instrumentation coefficient corrects for the efficiency of conversion of incident gamma rays to the final electrical pulses. The instrumentation coefficient turns out to be a function of frequency (Schimschal, 1980b). Two calibration test sources were used: cobalt-60 and thorium-232. When plotted on a semi-logarithmic plot, values for intermediate energies were obtained with sufficient accuracy (fig. 2). Since spectral tools deteriorate with time, leading to a broadening of the individual spectral peaks, experiments were performed to duplicate spectral envelopes obtained in the Grand Junction test pits with bucket models.

The probe was put into a plastic pipe, which was centrally located in a 20-liter plastic bucket. The bucket was filled with clean quartz sand. After placing a test source on the outside of the bucket, the shape of recorded spectrum resembled that obtained in the Grand Junction test pits. 


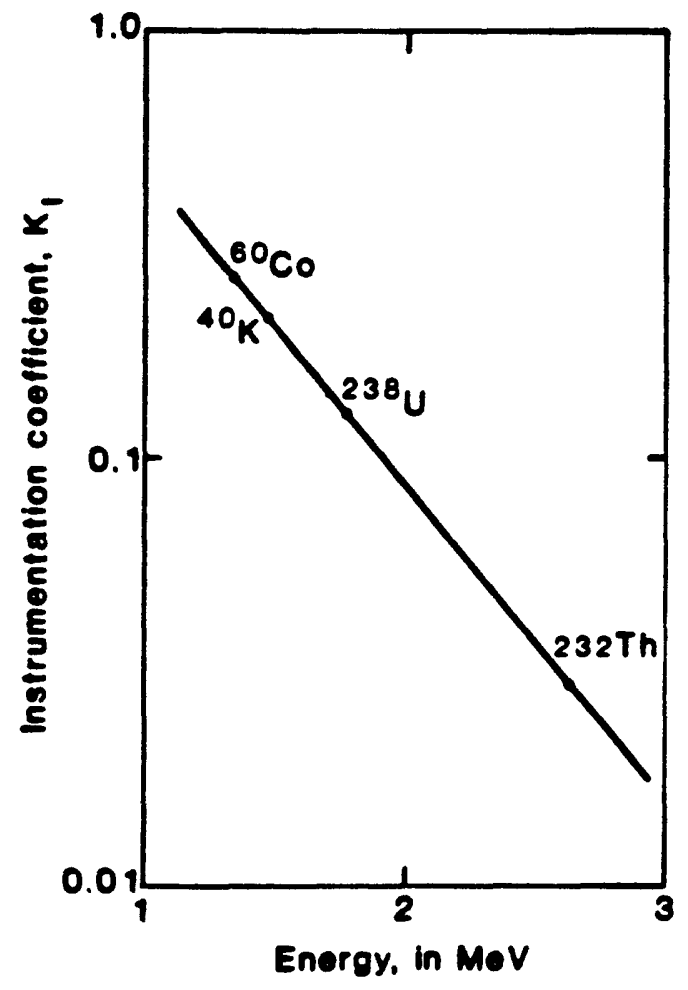

Figure 2.--Calibration for instrumentation coefficient. 
Earlier experimentation with a variety of quartz sand and gravel mixtures with or without water in the bucket model had shown negligible differences in the shape of the spectrum in the range of interest. The inhole spectrum of potassium in granite with negligible thorium or uranium contribution is shown In figure 3. Spectra recorded in the bucket filled with quartz sand with a small container with potassium hydroxide placed outside the bucket to simulate the effect of potassium in rock are shown in figures $4 a, 4 b$, and $4 c$ for comparison. By obtaining spectral shapes in this expedient manner at the borehole one may adjust windows for the continuous logging runs accordingly.

\section{Data analysis}

Gamma radiation spectral amplitudes corrected for spherical spreading and attenuation effects were calculated from a computer program that was originally developed for radioactive waste disposal studies (Schimschal, 1981). The results from this computer program are shown in figure 5. The geometric effect of crystal and borehole environment, called the geometric coefficlent, $K_{G}$, has been plotted as a function of layer thickness. As shown in figure 5, for the given conditions of crystal and borehole size, and the given rock attenuation; $K_{G}$ reaches a maximum value and remains constant for layer thicknesses greater than 80 to $90 \mathrm{~cm}$ because the effective radius is 80 cm. The effective radius was chosen that contributions beyond this radius are negligible. Input parameters for the program (porosity, density, and hole size) were obtained from neutron, gamma-gamma, callper logs, and core information. The maximum porosity on the neutron logs was about 3 percent and 1t was neglected. Core and log derived densities showed the density of the granite to be $2.62 \mathrm{~g} / \mathrm{cm}^{3}$ (grams per cubic centimeter). The parameters included in $K_{G}$ in figure 5 are: Porosity, 0 percent; granite density, 


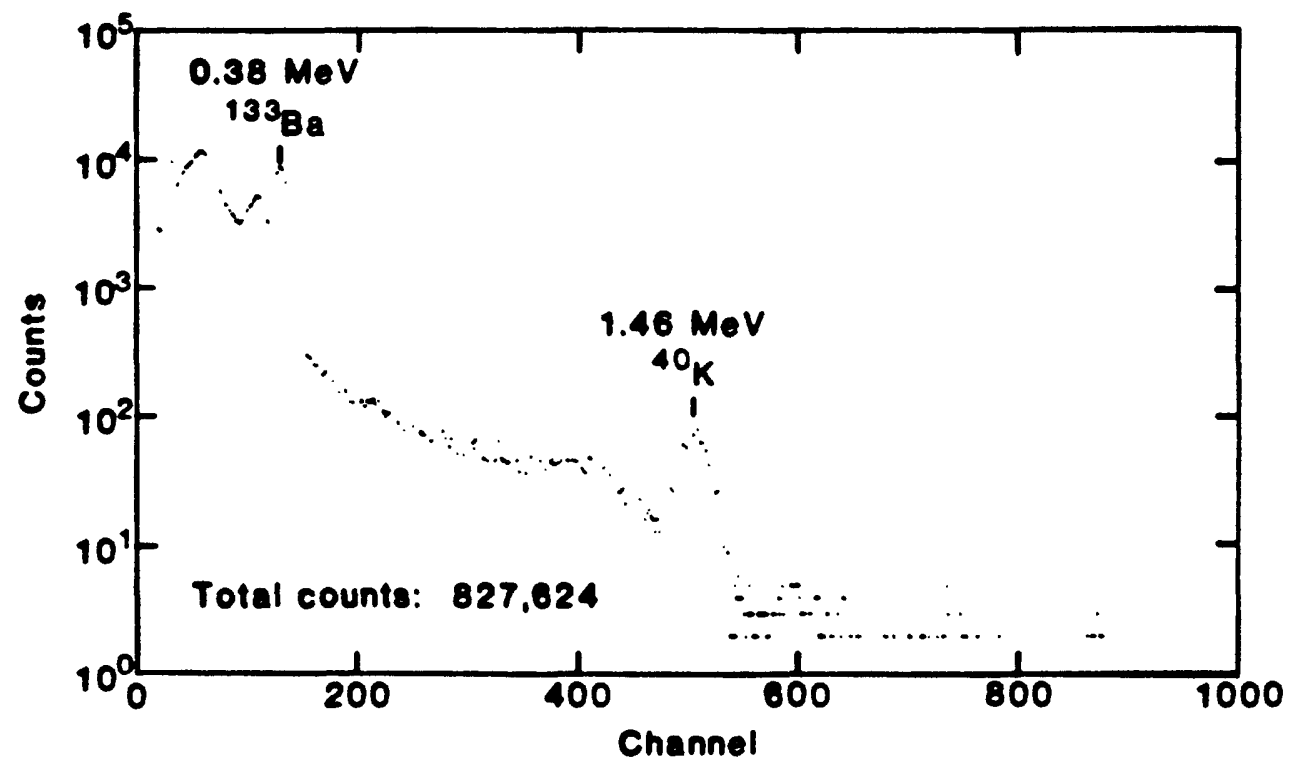

Figure 3.--Inhole spectrum for potassium in granite, showing little contamination from thorium or uranium; the barium peak was used for calibration. 


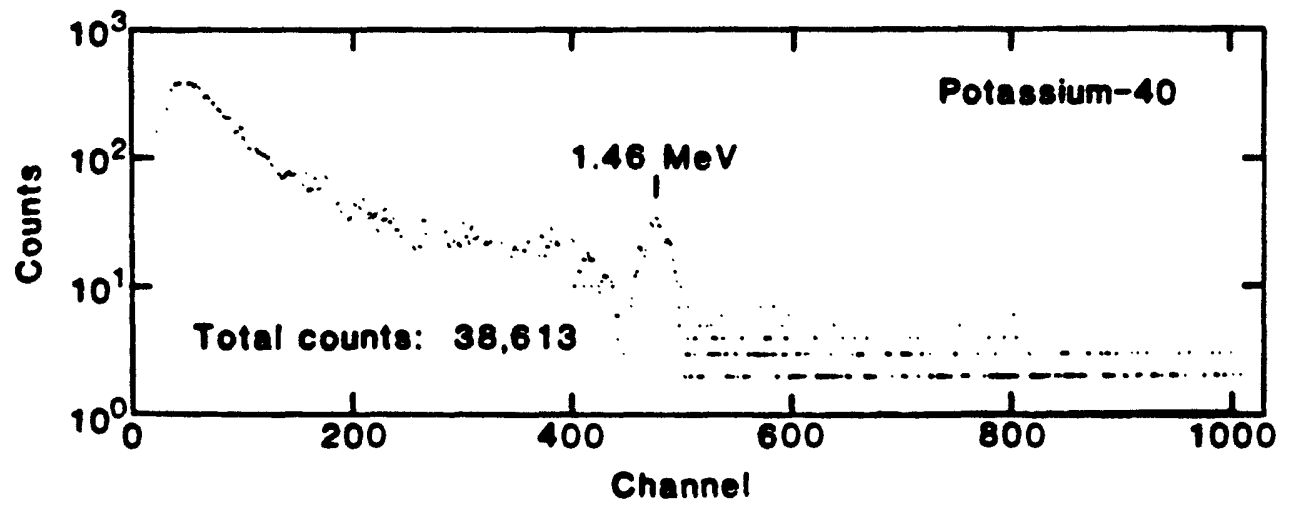

Figure 4a.--Potassium spectrum obtalned from bucket model. 


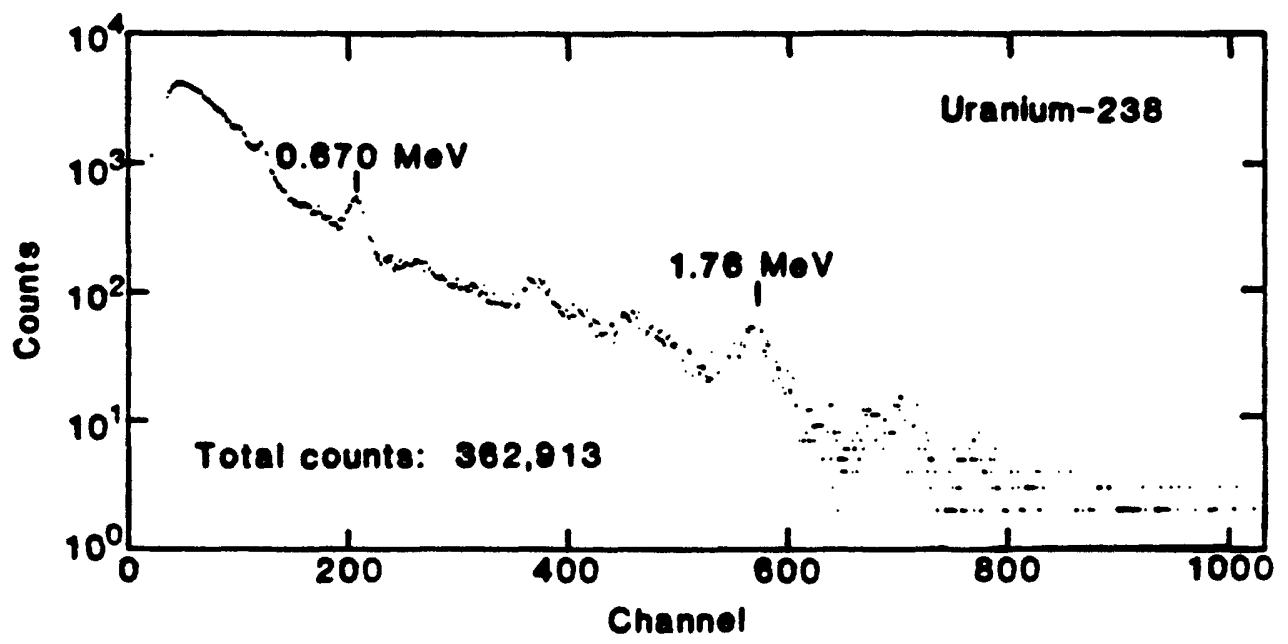

Figure 4b.--Uranium spectrum obtained from bucket model. 


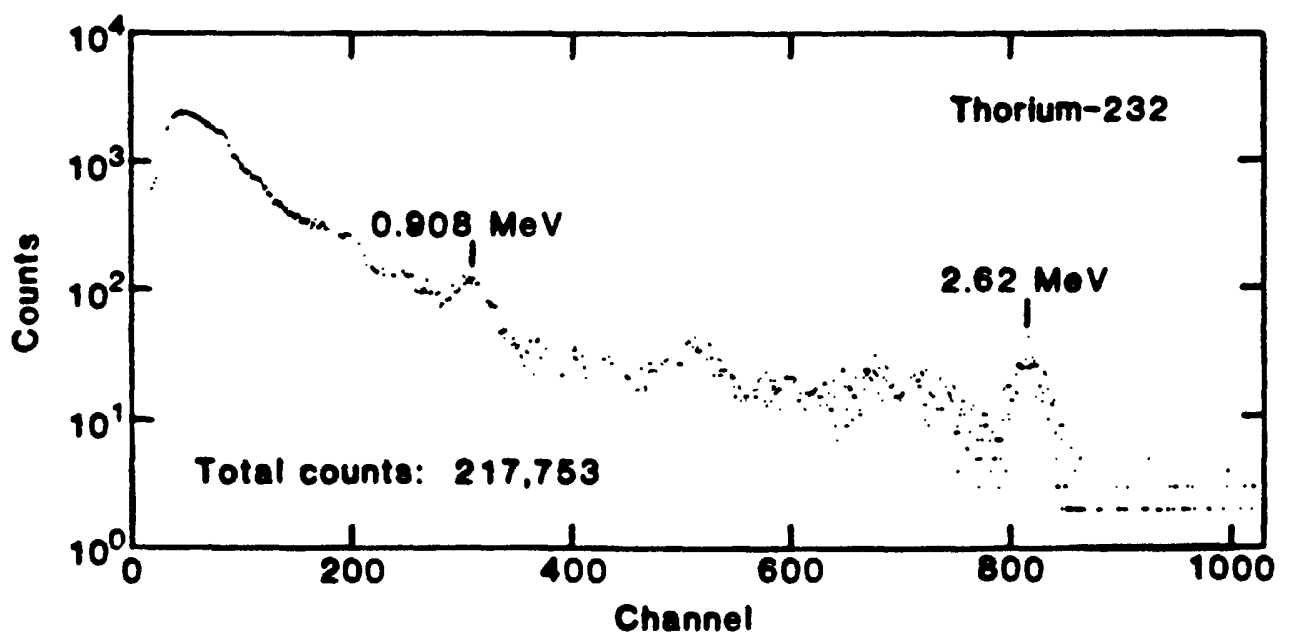

Figure 4c.--Thorlum spectrum obtalned from bucket model. 


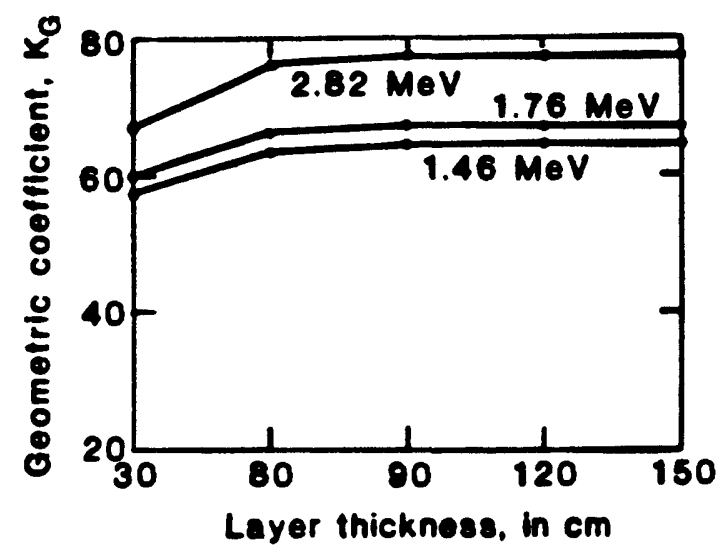

Figure 5.--Geometric coefficient calculated using the following paramters: Porosity, 0 percent; granite density, $2.62 \mathrm{~g} / \mathrm{cm}^{3}$; borehole radius, $3.81 \mathrm{~cm}$; crystal s1ze, $32100 \mathrm{~mm}$; effective radius, $80 \mathrm{~cm}$; and borehole fluld density, $1 \mathrm{gm} / \mathrm{cm}^{3}$. 
$2.62 \mathrm{~g} / \mathrm{cm}^{3}$; borehole radius, $3.81 \mathrm{~cm}$; crystal size, $32 \times 100 \mathrm{~mm}$; effective radius, $80 \mathrm{~cm}$; and borehole fluid density, $1 \mathrm{gm} / \mathrm{cm}^{3}$.

Energy calibration and spectral stripping or separation of signal from background of the fleld data were accomplished using a computer program. Part of this analysis for stationary spectra involves the matching of type spectra with field spectra. A detailed discussion of stripping ratio calculation is found in Lovborg et al. (1980). Stripping ratios were obtained from bucket type spectra. Counts under the peak areas were fitted by a Gaussian distribution, summed, and converted to intensity, in picocuries $(0.037$ counts per second $=1$ picocurie). Equation (1), given below, was used for subsequent interpretation.

$$
I_{0}=\frac{I_{T}}{\gamma K_{I} K_{G}}
$$

where

$$
\begin{aligned}
I_{0} & =\text { concentration, in picocuries per cubic centimeter; } \\
I_{T} & =\text { intensity of peak area, in picocuries; } \\
\gamma & =\text { gamma abundance for a given spectral peak, in percent; } \\
K_{I} & =\text { instrumentation coefficient obtained from probe cal1- } \\
& \text { bration (fig. } 2) \text {, and } \\
K_{G}= & \text { geometric coefficient obtained from figure } 5 .
\end{aligned}
$$

An additional simplification to streamline data analysis was the assumption that for all stationary data plotted, the layer thickness was $90 \mathrm{~cm}$. If the layer is actually thinner, an error will result.

The results of the data analysis were shown in table 1. Values shown in table 1 have been plotted in figures 6,7 , and 8 . Both the potassium and uranium data were stripped using bucket-derived type spectra (figs. $4 \mathrm{~b}$ and 
Table 1.--Data analysis

[A11 values are given in picocuries per cubic centimeter]

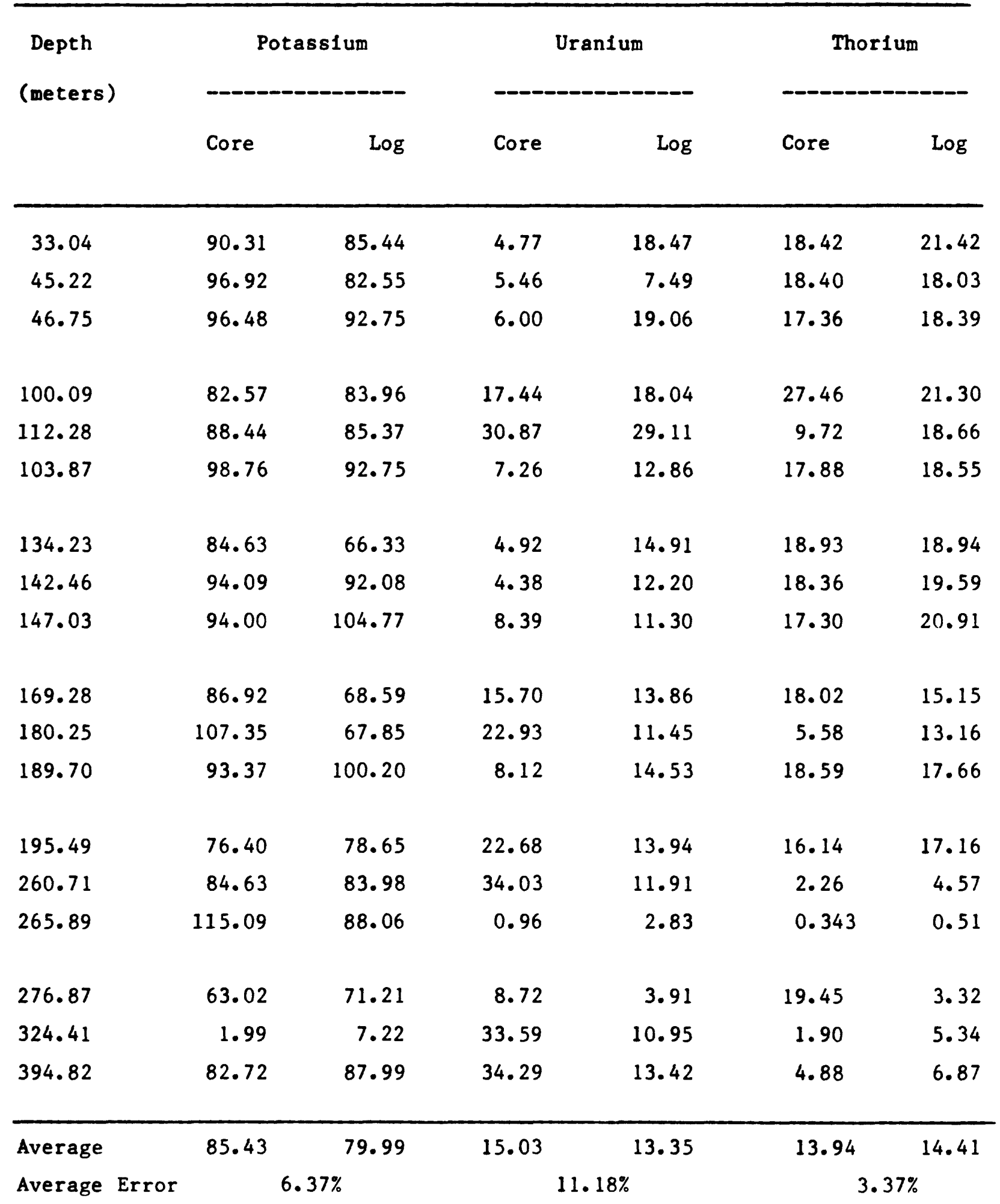




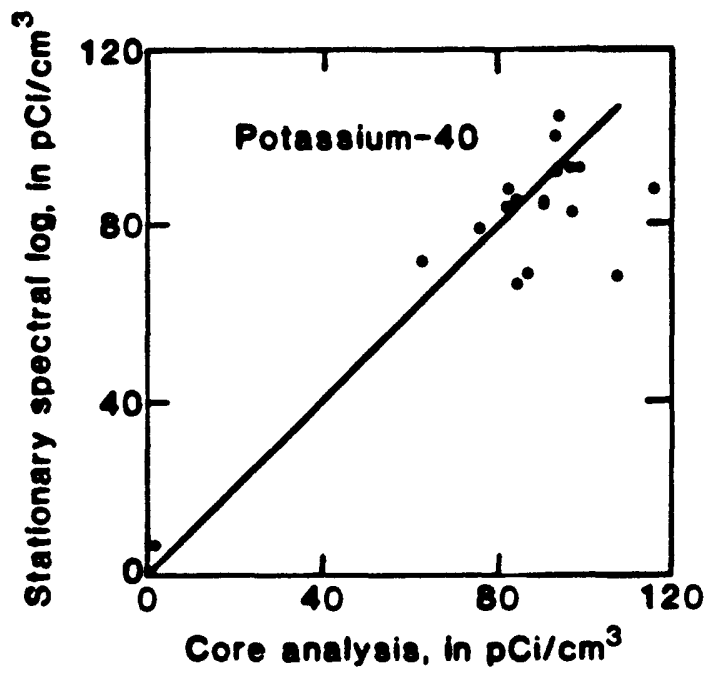

Figure 6.--Comparison of laboratory analysis with borehole lognalysis for potassium. 


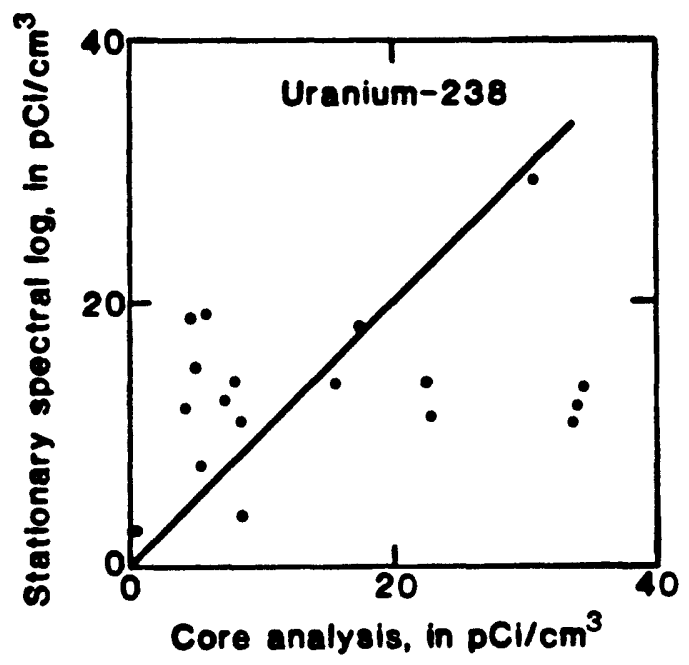

Figure 7.--Comparison of laboratory analysis with borehole log analysis for uranfum. 


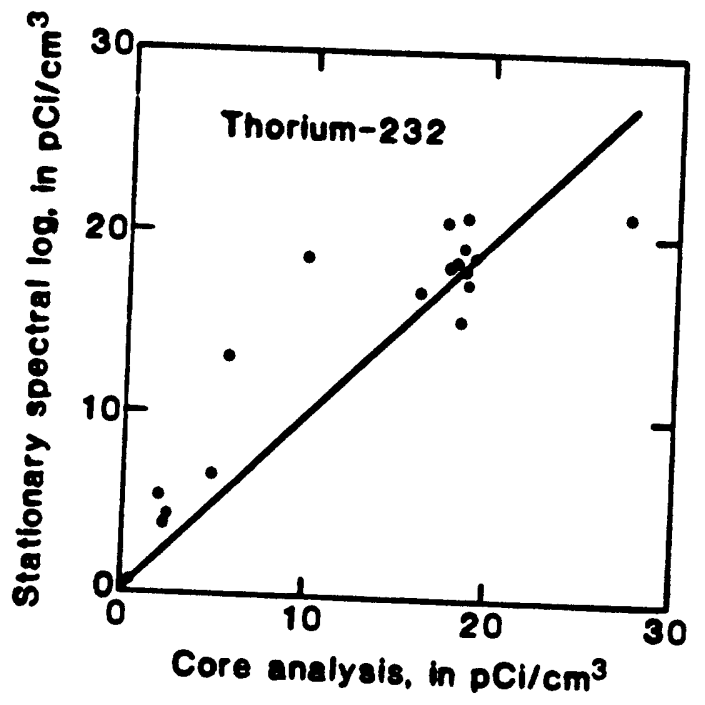
Figure 8.--Comparison of laboratory analysis with borehole log analysis for
thorium. 
4c). There is reasonable agreement between core and stationary borehole data for potassium (fig. 6) and thorium (fig. 8).

The uranium plot (fig. 7) shows more scatter. This is interpreted as largely being due to disequilibrium and to a chemical redistribution of the easily soluble and transported uranium compounds (Stuckless et al., 1977). In addition, there is a possibility that the distribution of uranium represented by core is not the same throughout a larger volume, is nonhomogeneous, or perhaps disseminated in small fractures.

The continuous logs were stripped using a computer program and the stripping ratios developed for the stationary spectra. The computer program first strips (or subtracts) from the field data the contribution from the thorlum. The resulting log represents the contribution from the uranium and potassium. The potassium $\log$ is obtalned by stripping the contributions of both thorium and uranium from the field data.

A section of a continuous $\log$ is displayed in figure 9. A 7-polnt or 90$\mathrm{cm}$ smoothing was applied to the original digitized data. The stationary spectra, the continuous $\mathrm{log}$, and core data are plotted for comparison. Coincident points on this log applies to points where laboratory core data and stationary spectra coincide.

\section{CONCLUSIONS}

The results of this study indicate that, for improved accuracy in Interpretation, a continuous $\log$ needs to be obtalned prior to the selection of cores or stationary spectral logs. This helps in the selection of a representative interval. A continuous log callbrated with properly selected stationary spectral logs may well be the most efficient and accurate approach in the quantitative determination in conjunction with multiple window logging 


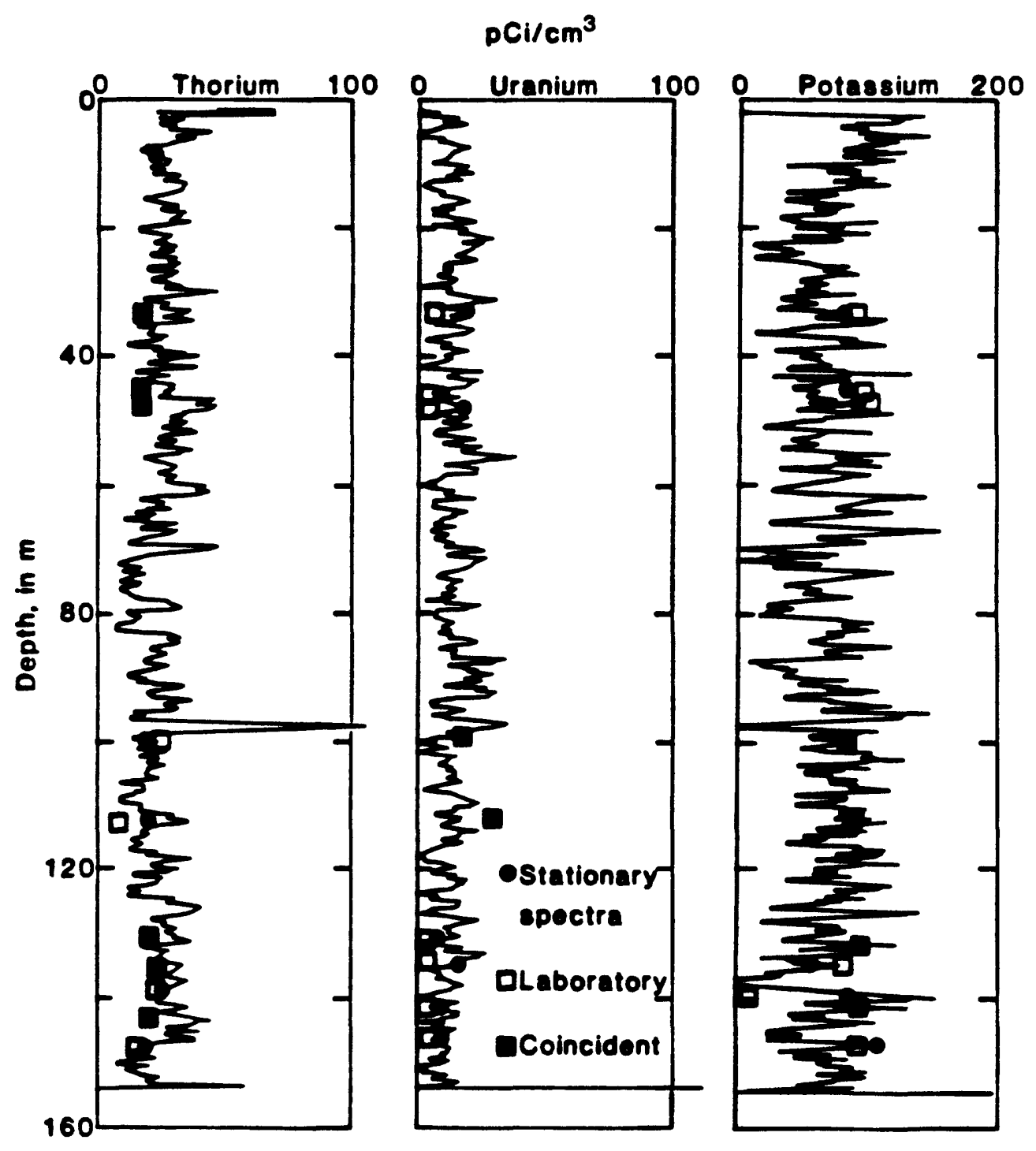

Figure 9a.--Stripped continuous log data compared to stationary spectra with laboratory core analysis--depth interval 0 to $155 \mathrm{~m}$. 


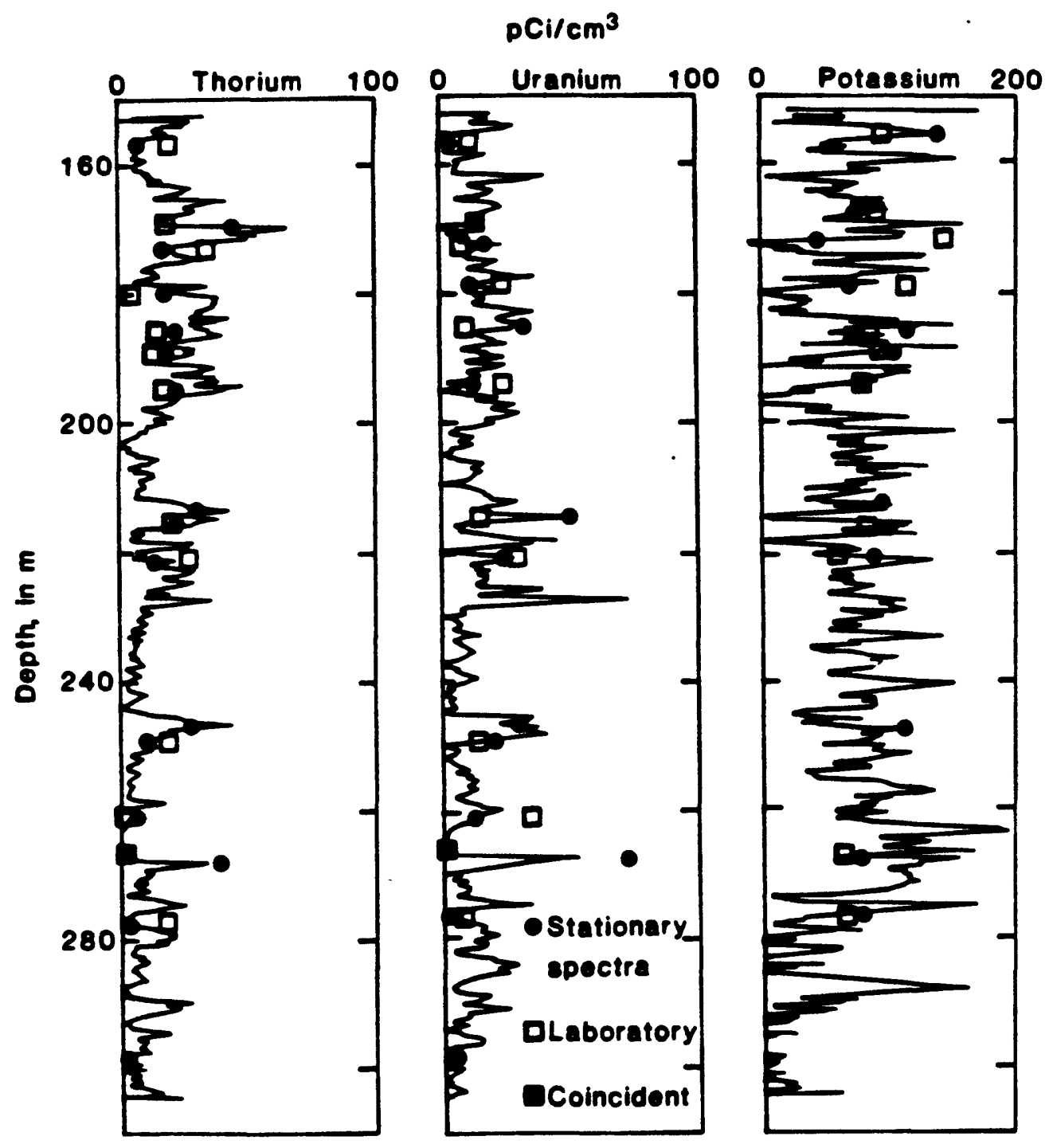

F1gure 9b.--Stripped continuous log data compared to stationary spectra and laboratory core analysis--depth interval 155 to $305 \mathrm{~m}$. 


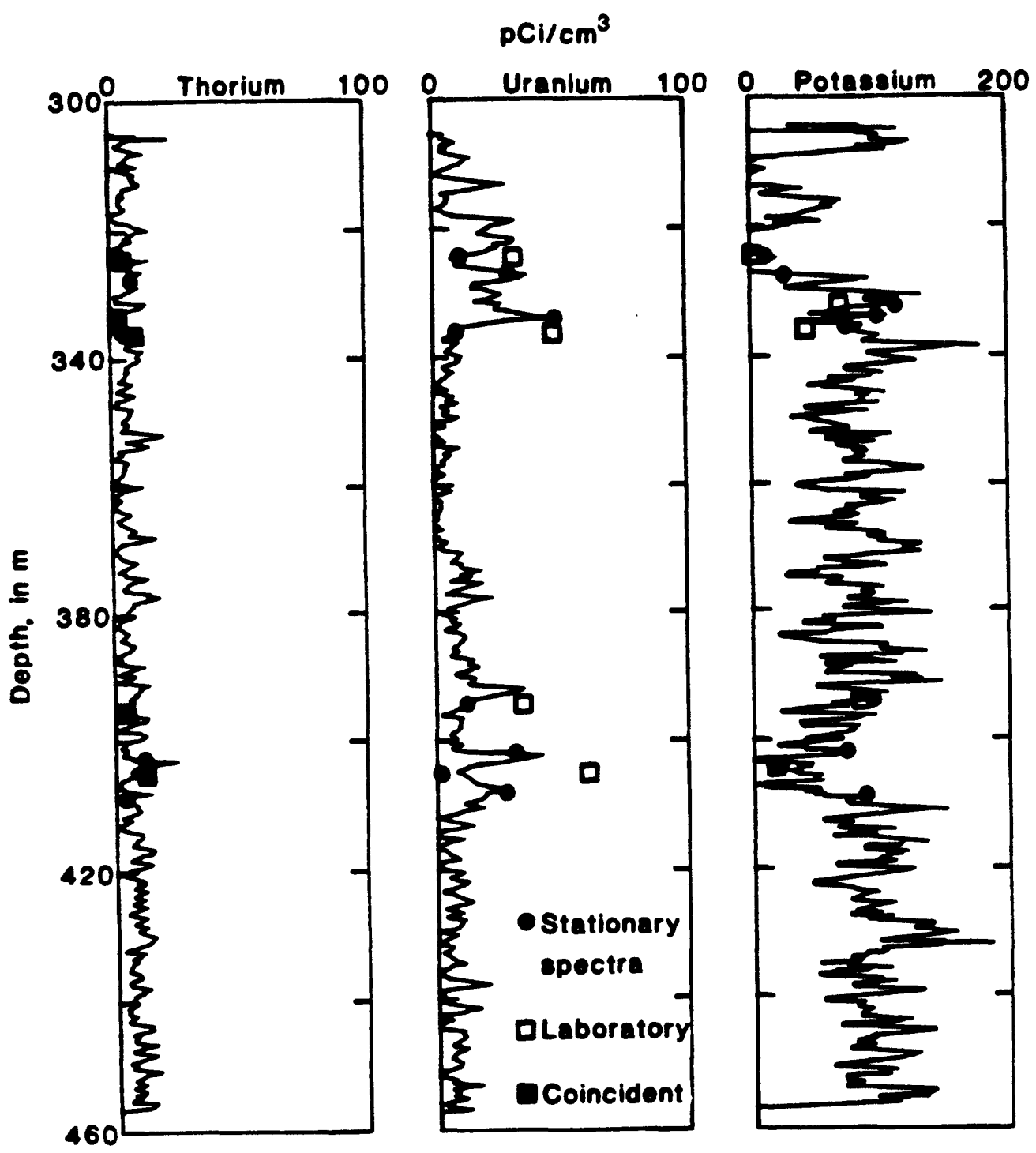

Figure 9c.--Stripped continuous log data compared to stationary spectra and laboratory core analysis--depth interval 305 to $463 \mathrm{~m}$. 
and subsequently improved layer definition, a calculation for each individual layer adequately represented on the continuous $10 \mathrm{~g}$ could be justifled. Even with the simplifying assumptions used in this study, reasonably accurate estimates of radioisotope concentrations can be obtained. 


\section{REFERENCES CITED}

Conaway, J.G., Bristow, Quentin, and Killeen, P.C., 1980, Optimization of gamma-ray logging techniques for uranium: Geophysics, v. 45, no. 2, p. 293-311.

Lóvborg, L., Nyegaard, P., Christiansen, E.M., and Nielsen, B.L., 1980, Borehole logging for uranium by gamma-ray spectrometry: Geophysics, v. 45, no. 6, p. 1077-1090.

Schimschal, Ulrich, 1980a, Scintillation detectors in gamma spectral

logging; geometry, absorption, and calibration: U.S. Geological Survey Open-File Report 80-688, p. 1-29. 1980b, Quantitative effects of 11thology, borehole environment, and probe design in gamma spectral logging with scintillation crystals: The Log Analyst, September-October 1980, p. 3-10. 1981, A mathematical model of gamma ray spectrometry borehole logging for quantitative analysis: U.S. Geological Survey Open-File Report 81402,28 p.

Stuckless, J.S., Bunker, C.M., Bush, C.A., Doering, W.P., and Scott, J.H., 1977, Geochemical and petrological studies of a uraniferous granite from the Granite Mountains, Wyoming: U.S. Geological Survey Journal of Research, v. 5, no. 1, p. 61-81. 